\title{
10 Tips for a Great Health Care Research Article
}

\author{
Kathleen A. Fairman, MA
}

$\mathrm{T}$ he JMCP editors are often asked for advice on how to write a research article that will succeed in the rigorous JMCP peer review process. We are always pleased to provide authors with guidance about the critically important task of transparently reporting research methods and findings. However, we emphasize that good writing is only one component of the necessary work. At its heart, writing a good research article fundamentally depends on having a good research project to write about. In other words, producing a credible and useful research report for peer reviewers-and, ultimately, for readers-is a function of the entire research process, including literature review, planning, project organization, execution of the study methods, analysis, write-up, and effective response to the comments of colleagues and peer reviewers. Following is a high-level summary of best practices (Table 1). ${ }^{1}$

\section{Focus on Design Quality}

Quality-grading systems for research universally recognize that randomized designs, in which study subjects have a mathematically determined (known) probability of selection into each study cohort, produce results of superior internal validity (accuracy of inference) compared with observational designs, in which the investigator observes the outcomes of a cohort assignment process that is determined by participants (e.g., patients, physicians) and results in an unknown probability of selection. ${ }^{2}$ For example, in the Grading of Recommendations Assessment, Development, and Evaluation (GRADE) standards, the highest grade that an observational study can earn is a "C" on a scale of "A" to "D." "3,4

However, lower-quality randomized studies - such as those in which allocation concealment was compromised (e.g., the investigator or staff members were able to interfere in the group assignment process), or external validity (applicability) is suboptimal-also earn lower grades. ${ }^{3}$ One common source of a grade reduction for problematic external validity is an outcome measure of questionable importance in clinical practice, such as a biomarker that has not been clearly linked to a "hard" endpoint outcome (e.g., mortality, hospitalization). ${ }^{3}$ Another common problem is a trial that poorly represents the group in which the intervention will be applied in routine practice, such as a sample that excluded patients with diabetes although a large proportion of patients who will use the study drug in routine practice have diabetes. ${ }^{3}$

Key reasons for the superiority of randomized over observational designs for internal validity in health care research include the following: (a) regression to the mean, a mathematical phenomenon in which, on average, high values (e.g., cost, uti- lization) decline over time regardless of intervention, creating the erroneous impression that a study intervention caused the decline, ${ }^{5}$ (b) confounding, in which both a hypothesized predictor and outcome are caused by a third factor, creating the erroneous impression that the predictor caused the outcome (e.g., the "healthy adherer" effect, in which healthy lifestyles/ behaviors cause both medication adherence and positive health outcomes, creating a partly spurious association between adherence and outcomes); 6,7 and (c) sole reliance on crosssectional association without establishing a causally plausible temporal sequence of events (e.g., measuring the association between use of Drug A and an emergency room (ER) visit for Outcome B in the same 6-month time period, without assessing whether initiation of Drug A preceded or followed the ER visit). ${ }^{8}$ Because it is common for conclusions based on even high-quality observational research to be modified or reversed once subjected to the more rigorous test of a randomized controlled trial (RCT), a topic that has not yet been analyzed using a randomized design should be considered understudied and, if it has potential implications for patient care, should be a critically important focus of research efforts.

A notably consequential recent example is the Action to Control Cardiovascular Risk in Diabetes (ACCORD) trial, which randomized patients with high cardiovascular risk and type 2 diabetes to standard glycemic control targeted to a hemoglobin Alc level of $7 \%-7.9 \%$ or to intensive glycemic control targeted to Alc less than $6 \% .{ }^{9}$ Contrary to previously published high-quality observational analyses indicating a strong epidemiological association between normal $(<6 \%)$ Alc levels and reduced rates of morbidity/mortality in patients with type 2 diabetes, the ACCORD trial found that the "lower is better" treatment strategy actually increased mortality by an estimated 3 deaths per 1,000 treated patients per year, or approximately $22 \% .{ }^{9}$ Numerous additional examples of clinical guidance that was based on observational research but ultimately refuted by RCT evidence are available in both health policy and clinical literature. ${ }^{2,10,11}$

For these reasons, it is best to use a randomized design when possible. If only observational analysis is feasible, the credibility and accuracy of the findings can be enhanced by (a) creating study groups (i.e., intervention and comparison) that are similar in every respect except the intervention; (b) establishing the temporal sequence of events in designing the study (e.g., measuring whether use of Drug A or an ER visit for Outcome B occurred first); and (c) examining the plausibility of the hypothesized causal construct for the observed association (e.g., assess not only all-cause 


\section{TABLE 1 10 Tips for a Great Health}

Care Research Article

1. Focus on design quality.

2. Determine what is known about the topic before beginning the study

3. Use quality control procedures and work product review for every project.

4. Check the math.

5. Employ a sensible data analysis.

6. Remember the original purpose of administrative claims data.

7. Explore alternative explanations.

8. Consult a reporting guideline.

9. Appreciate peer review comments, especially if they are erroneous

10. Recognize that methods matter.

aAdapted from: Fairman KA. Health Care Research Done Right. ${ }^{1}$

health care utilization, but also disease-specific utilization, in interpreting a relationship between treatment and outcomes).

\section{Determine What Is Known About the Topic Before Beginning the Study}

$J M C P$ requires that authors include in every submission (except commentaries and letters) quantitative, specific bullet points describing (a) what was already known about the topic prior to the present study and (b) what the present study adds. We do this because an investigator who builds a project on the foundation of previous work greatly increases his or her likelihood of studying topics that represent what decision makers really need to know, using appropriate and state-of-the-art methodologies, and interpreting the findings correctly. One of our least favorite editorial tasks is advising authors that the topic of their paper has been studied in numerous previous publications not cited in the submitted article (i.e., apparently missed in the literature review), especially if the previous work used methods that were superior to those of the present study. In these unhappy circumstances, the authors have often wasted what may have been a substantial amount of time and effort, either by studying an already thoroughly analyzed phenomenon or by using an inappropriate, outdated, or incomplete method.

To avoid these problems, it is critically important to perform a thorough literature review before beginning data collection, both to determine the gaps in available knowledge-which will eventually become the "what this study adds" statement-and to learn about methods used in previous work on the topic. A good way to get an overview both of the gaps that should be addressed by the present study and of the methods used previously is to construct a literature summary table that shows key research elements: who (sample characteristics and size), what (intervention), when (time periods for selection of study subjects and for follow-up), findings (key quantitative results), and implications or comments (e.g., critiques of the method that might reflect gaps in the available information). ${ }^{1}$ By revealing patterns in the literature, the summary table provides guidance in making decisions throughout the project and is well worth the time necessary to create it. In reality, the investment of time to produce a literature summary table is quite small compared with the "backtracking" that must sometimes be done when researchers make the mistake of beginning the project without the necessary foundation.

\section{Use Quality Control Procedures and Work Product Review for Every Project}

Projects conducted by even the most talented and dedicated investigators have been compromised, sometimes severely, by failure to use quality control procedures in managing data files and computer programs, resulting in mismanagement or miscommunication of data analyses and, ultimately, dissemination of erroneous information. ${ }^{1,12}$ For example, a popular book by Weitzman, The Divorce Revolution (1985), ${ }^{13}$ was cited in hundreds of journal articles in less than 9 years following its publication, won the American Sociological Association's prestigious "Distinguished Contribution to Scholarship" award in 1986, was the subject of congressional testimony, and by 1996 resulted in the passage of 14 new divorce laws in the state of California alone. ${ }^{14-16}$ Yet, much of the book's influence was based on a key finding, an assessment of standard of living for women compared with men, that in 1996 was determined to be wrong - attributable to keying or programming mistakes committed by a Stanford research assistant working under Weitzman's supervision. ${ }^{14-16}$

How did such a consequential error occur? Researchers who attempted to obtain a copy of Weitzman's data to replicate her findings were unable to do so for several years after the book's publication. Once granted access, they reported that the data were "disorganized and unreviewable," according to a law review account by McNeely (1998). ${ }^{17}$ After a painstaking investigation and analysis, Social Science Research Council sociologist Richard Peterson concluded in 1996 that "it is clear that the results reported in The Divorce Revolution for the change in the average standard of living... could not have been derived from the data and methods described in the book."15

One portion of Weitzman's detailed assessment of how the error occurred is particularly telling: "I now report, with chagrin," Weitzman wrote in 1996, "that I myself had questioned the 73 percent decline in women's post-divorce standard of living when the figure was first computed and asked my computer expert on three separate occasions to verify it. He said he had done so, with the same result, and I accepted that."16 Weitzman's experience illustrates that asking even the most talented and smart researcher to verify his or her own work is an ineffective method of quality control. Because we are all fallible human beings, completely preventing error is impossible; instead, we must use quality control procedures to prevent the errors that do occur from damaging the accuracy of the results that we publish.

It is also informative to note that the sociopolitical atmosphere of the time contributed to the sharp contrast between 
the enormous popularity of the book and the suboptimal quality of the research on which it was based. Weitzman's work, according to McNeely, was "trumpeted in the news media and various publications as proof that divorce laws actually favored men."17 Even after the analysis was discredited, "many policy makers and judges failed to recognize the clear errors of Weitzman's work and conclusions" because "her study told them what they wanted to hear." ${ }^{17}$ In other words, the more compelling and "crowd-pleasing" a researcher's findings seem to be, the more tempting it is to skip the all-important procedures necessary to verify that the findings are accurate. The unfortunately common results of yielding to this temptation are lost time, lost credibility, or worst of all, harm caused to the people whom the work was originally intended to help.

Recommended quality control procedures, which take little time but yield enormous benefits, include the following:1,12

Verify Data upon Receipt. Miscommunications about the structure and content of data files occur frequently. To prevent these misunderstandings from causing wasted time and dissemination of erroneous information, confirm that data files contain what you believe they should contain as soon as you receive them. For example, if a dataset should contain pharmacy claims for antidepressant users aged 65 years or older, verify that all patients in the dataset are in the specified age range and that each patient has at least 1 claim for an antidepressant medication. If studying what you have been told is a 3-tier copayment structure of $\$ 5 / \$ 15 / \$ 25$ for generic, preferred brand, and nonpreferred brand drugs, respectively, verify that the copayments documented in the pharmacy claims match the expected cost-sharing amounts. If modifying a decision analytic model, first replicate the model to ensure that you understand it, and then make the planned modifications. These are just examples; the specific procedures will vary depending on the analysis and files. The general idea is to ensure before using any data source that its contents are understood.

Track Data Files as They Are Created. Maintain a log of data files created during the course of each project. The log should show the date on which the file was created, the name or initials of the person who created the file, the location of the file (e.g., "c:lprojects2012ltier3"), the name of the program that was used, and any notes about why the data file was created (e.g., "Incorporated new completed patient surveys received after submission deadline."). This log enables the analyst, or any other staff member if for some reason the analyst is unavailable, to recreate the file easily if necessary to answer a question, respond to a request from an editor or peer reviewer, or recover from a computer "crash."

Maintain a Publication Tracking Record. For every publication or presentation, maintain a record showing the program, output file, and data file that were used to create each table or figure, along with a run date for each. For example, an entry for the first table in a research article, a table of demographic characteristics, might show a program name "demographic2. sps," an output file name of "demographics.spo," a data file "demo_clinical.sav," and a run date of 03.11.12.

This record enables easy and rapid responses to questions from peer reviewers (e.g., "Does the patient characteristics table represent the sample before or after removing users of Drug A?" "Does the 'cardiovascular drug' category include antihypertensives?"). The record also facilitates compliance with requests for changes or sensitivity analyses by eliminating the need for a time-consuming trial-and-error process, such as searching through the computer for files, trying to replicate the analyses with each file until the correct file is identified.

Annotate and Check Code. As the analyst works, he or she should include comments throughout describing what the code is intended to do (e.g., "Create index date, defined as the first claim for Drug A in 2011;" "Measure treatment delay, defined as time from first diagnosis of Disease $\mathrm{X}$ to first treatment with Drug Class B"). The code should also contain verification steps so that anyone reading through the program output can verify that the code accurately achieved its objectives. For example, the creation of an age group variable might be followed by a frequency table that shows the minimum and maximum ages for each age group. These verification steps address not only coding errors (e.g., inadvertently omitting age 30 from the category "30-39 years") but also unexpected data patterns (e.g., age is missing or age $=994$ years).

Use a Work Product Review System. Prior to the release of research findings, the data analysis for every project should be checked for accuracy no matter how urgent the need for the information. Internal work product review can be performed by a supervisor, colleague, or fellow student, with both the analyst and the reviewer sharing responsibility for the reporting of accurate findings. The work product reviewer should examine the a priori analysis plan, computer output files, and study report tables and figures to ensure that all work has been produced according to specification.

\section{Check the Math.}

One of the most common errors that we see in manuscripts submitted to JMCP is incorrectly calculated percentageseither use of the wrong denominator, simple calculation errors, or rounding errors. Depending on the volume and degree of error, this problem can result in misinterpretation of data, a peer reviewer assessment that basic mathematical mistakes reflect such a lack of skill that the manuscript should be rejected, or cranky editors. To avoid these problems, ensure that the calculation matches its purpose and check it for accuracy. To profile a group (e.g., describe the characteristics of users of Drug A), the denominator to be used for all percentages is the total group size (e.g., the total number of patients using Drug A). To determine predictors of an outcome (e.g., adherence to Drug A), the denominators will generally represent the sizes 
TABLE 2 Monthly Versus Per Member Per Month Cost

\begin{tabular}{c|c|c}
\hline Cost (\$) & Enrolled Months & Monthly Cost (\$) \\
\hline 30,000 & 1 & 30,000 \\
\hline 2,000 & 12 & 167 \\
\hline
\end{tabular}

Simple average of monthly costs: $\$ 30,167 \div 2=\$ 15,084$

Actual per member per month cost: $\$ 32,000 \div 13=\$ 2,462$

of the independent variable groups. For example, to determine if age is a predictor of adherence to Drug A, a table might show the percentage of those aged 18-34 years who are adherent to Drug A (denominator $=$ count of those aged 18 to 34 years), the percentage of those aged 35-44 years who are adherent to Drug A (denominator $=$ count of those aged 35 to 44 years), and so on for each age group. Additionally, it is helpful to ensure that calculation and rounding of percentages are performed in an automated fashion; for example, because JMCP uses the format $\mathrm{XX} . \mathrm{X} \%$ (percentage values expressed to 1 decimal), set the statistics package to round output to 1 decimal. All calculations should be verified as part of the work product review process.

Another common error is failure to take unit of analysis into account in the data analysis. A typical mistake is equating the simple average of monthly cost with a per member per month (PMPM) value. For example, consider a simple case of a 2-member health plan (Table 2). The health plan's data display a typical pattern; expenditures for health care services accelerate in the last few months of life. ${ }^{18}$ One member is enrolled for 1 month prior to death and incurs health care expenditures of $\$ 30,000$; the other is enrolled for 12 months with expenditures of $\$ 2,000$. The simple average of monthly costs greatly overstates the true PMPM amount.

Several options exist to address problems of this type.The most commonly used method is weighting, that is, mathematically treating each case as if it represents its total number of enrolled months, while holding total sample size constant.,19

\section{Employ a Sensible Data Analysis}

Additional common analytic errors that we see in manuscripts submitted to JMCP are overreliance on advanced statistics and/ or lack of focus in the data analysis-in other words, table after table employing various advanced multivariate or decision analytic techniques without any clear connection to the study research questions or hypotheses. These data presentations tend to confuse readers and reduce the credibility and usefulness of the findings.

To avoid these problems, follow the advice provided in guidelines for reporting quantitative results. ${ }^{20,21}$ Employ advanced statistical techniques when necessary-for example, to correct for confounding, to perform forecasting, or to apply a series of hypothetical assumptions to predict likely future outcomes. However, report both unadjusted and statistically adjusted results; this approach facilitates understanding of the effects of the statistical technique on study findings and provides readers with easily understood metrics, such as percentages, means, and medians. ${ }^{21}$

Additionally, remember the limitations of these techniques when interpreting the data. A decision analytic model is only as valid as the assumptions on which is based. Most multivariate techniques (e.g., linear regression, logistic regression) adjust only for measured confounders. Those techniques that adjust for unmeasured confounders (e.g., instrumental variable analysis, fixed-effects analysis) have limitations as well; instrumental variable analysis can be difficult to execute because of problems in identifying an appropriate variable to use as the "instrument,"22-24 and fixed-effects analysis, as its name implies, adjusts only for unobserved factors that do not vary over time (e.g., employment sector).

Finally, as reporting guidelines for observational analysis point out, even the highest-quality multivariate analysis does not prove a causal relationship; advanced statistical techniques are often useful but not a perfect substitute for strong research design. ${ }^{21}$ Thus, validation of the statistical analysis is important. For example, if the investigator hypothesizes that the cause of a relationship between use of Drug A and lower all-cause medical costs is attributable to reductions in ER visits for side effect $Q$, an analysis of rates of side effect $Q$ comparing users of Drug A with users of other drugs in the therapy class should be performed.

Additionally, the study report should make clear to the reader how the analytic method was determined and how the analysis directly informed the study hypotheses or research questions. Whenever possible, the report should present quantitative findings that have meaning for the reader, such as number needed to treat. The presentation of statistical findings should also include a measure of model quality, such as $\mathrm{R}^{2}$ for linear regression and the c-statistic for logistic regression analysis; these assess the degree to which the independent variables accurately predict or explain the dependent variable.,20,25

\section{Remember the Original Purpose of Administrative Claims Data}

In interpreting findings based on administrative medical and pharmacy claims data, it is important to remember that these data were not generated for research purposes. They are bills, used to calculate and generate payments. For this reason, they are not always ideally suited for every research purpose intended by the investigator. For example, in a health plan in which only 1 diagnosis is required for payment of a medical claim, a secondary diagnosis may be missing from the claim even if it is clinically correct. In a health plan that "carves out" its mental health benefits, claims for therapy visits for schizophrenia will probably be excluded from the dataset. And, in a health plan that does not cover Drug A unless a patient has 
Diagnosis B, a medical claim for a user of Drug A is more likely to have Diagnosis B than another diagnosis, even if the latter diagnosis is clinically correct. ${ }^{26,27}$

\section{Explore Alternative Explanations}

Examining alternative explanations for study findings, rather than focusing solely on the investigator's preferred or hypothesized explanation, is widely recognized as a key element of study quality. ${ }^{8,21}$ Sensitivity analyses should be used to examine various reasonable approaches to study methods, such as basing inclusion criteria on primary and secondary diagnosis instead of primary diagnosis alone, requiring 12 months of continuous enrollment after an index date rather than 6 months, or defining a "new start" based on a "washout" period of 6 months instead of 3 months. ${ }^{26}$ These decisions should be based primarily on the literature review performed at the start of the project, and there should be a particular focus on any changes to the a priori analysis plan that may have become necessary. For example, if the a priori plan called for a 12-month follow-up, but unexpected sample size limitations prompted the researchers to reduce follow-up to 3 months, a sensitivity analysis should examine the subgroup of study cases that were followed for the originally planned 12 months.

It is also often helpful to address questions that are unanswered in claims database research with a follow-up patient survey. For example, when questions arose about the results of a claims database analysis of prescription-filling patterns following a step-therapy edit, Cox et al. (2004) used both a mailed survey and a telephone survey to investigate. ${ }^{28}$ They identified several methods being used by respondents to obtain medication without generating a claim, such as obtaining samples, filling the prescription through a spouse's insurance, and using medication that was on hand prior to the step-therapy edit date.

Although the specific methods will vary depending on the project, the general idea of the exploration is to anticipate questions that readers are likely to have about the study findings and to include the answers in the study report. Peer reviewer comments are extremely helpful in this regard.

\section{Consult a Reporting Guideline}

The Enhancing the QUAlity and Transparency Of health Research (EQUATOR) network website (www.equator-network.org) contains specific, helpful guidance on reporting numerous types of health care studies. Prior to beginning the research project if possible, use the EQUATOR network's searchable database to find a reporting guideline that is appropriate for the study type being planned. ${ }^{29}$ Many of the guidelines have "explanation and elaboration" documents that present the rationale underlying the reporting standards as well as examples of articles that have used good reporting practices.

It is important to note that the purpose of good reporting is not to convey perfection in the design or execution of a study. Instead, good reporting is based on the recognition that no study is perfect. A good report presents methods and findings clearly to facilitate understanding of the strengths, weaknesses, and applicability of the research. ${ }^{21}$

\section{Appreciate Peer Review Comments, Especially if They Are Erroneous}

Peer reviewers typically represent, at least to some degree, the perspective of a journal's readers. If a peer reviewer misses a finding or misunderstands an argument in your article, chances are good that many readers will have the same point of confusion or concern. For this reason, peer review should be viewed primarily as an opportunity to learn how to communicate with readers rather than as a "hurdle" or barrier to publication. ${ }^{30,31}$ If a reviewer makes a comment that you believe is incorrect, try to determine what might have prompted the erroneous perception. If you are unable to identify the problem, ask the editors for help in understanding the reviewer's viewpoint, or respectfully refute the comment. Note that if 2 or more reviewers express the same concern, they have identified a problem that definitely must be addressed in the manuscript.

\section{Recognize That Methods Matter}

As many observers have pointed out, Weitzman's erroneous findings were, sadly, used for many years to make legislative and policy determinations about family law, as well as judicial rulings affecting child custody cases. ${ }^{14,17}$ Similarly in health care research, as the GRADE developers observed in 2008, failure to account for the quality of study methods has sometimes led to suboptimal care or even to patient harm. ${ }^{32}$ The investment of time necessary to produce high-quality health care research is more than offset by the benefits to a researcher's time, reputation, and peace of mind-and, most importantly, to the patients whom we serve.

\section{Author}

KATHLEEN A. FAIRMAN, MA, is Associate Editor and Senior Methodology Reviewer of the Journal of Managed Care Pharmacy.

AUTHOR CORRESPONDENCE: Kathleen A. Fairman, MA, Academy of Managed Care Pharmacy, 100 North Pitt St., Suite 400, Alexandria, VA 22314. Tel.: 602.867.1343;

E-mail:kfairman@amcp.org.

\section{DISCLOSURES}

Fairman is the author of Health Care Research Done Right, a textbook (in press) on which much of the material in this article is based. She has no other financial conflicts of interest. 


\section{REFERENCES}

1. Fairman KA. Health Care Research Done Right: A Journal Editor Shares Practical Tips and Techniques for High Quality and Efficiency. Denver, CO: Outskirts Press; in press.

2. Fairman KA, Curtiss FR. Rethinking the 'whodunnit' approach to assessing the quality of health care research-a call to focus on the evidence in evidence-based practice. J Manag Care Pharm. 2008;14(7):661-74. Available at: http://www.amcp.org/data/jmcp/661-674_FairmanCurtiss-Final.pdf.

3. McAlister FA, van Diepen S, Padwal RS, Johnson JA, Majumdar SR. How evidence-based are the recommendations in evidence-based guidelines? PLoS Med. 2007;4(8):1325-32. Available at: http://www.plosmedicine.org/ article/info\%3Adoi\%2F10.1371\%2Fjournal.pmed.0040250. Accessed April 24, 2012 .

4. Atkins D, Best D, BrissPA, et al.; GRADE Working Group. Grading quality of evidence and strength of recommendations. BMJ. 2004;328:1490-94. Available at: http://www.ncbi.nlm.nih.gov/pmc/articles/PMC428525/?tool= pubmed. Accessed April 24, 2012

5. Linden A. Estimating the effect of regression to the mean in health management programs. Dis Manage Health Outcomes. 2007;15(1):7-12

6. Simpson SH, Eurich DT, Majumdar SR, et al. A meta-analysis of the association between adherence to drug therapy and mortality. BMJ. 2006;333(7557):15. Epub 2006 Jun 21. Available at: http://www.ncbi.nlm. nih.gov/pmc/articles/PMC1488752/pdf/bmj33300015.pdf. Accessed April 24, 2012.

7. Curtis JR, Delzell E, Chen L, et al. The relationship between bisphosphonate adherence and fracture: Is it the behavior or the medication? Results from the placebo arm of the fracture intervention trial. J Bone Miner Res. 2011;26(4):683-88

8. Motheral B, Brooks J, Clark MA, et al. A checklist for retrospective database studies-report of the ISPOR Task Force on Retrospective Databases. Value Health. 2003;6(2):90-97. Available at: http://www.ispor.org/workpaper/research_practices/A_Checklist_for_Retroactive_Database_StudiesRetrospective_Database_Studies.pdf. Accessed April 24, 2012.

9. National Heart Lung and Blood Institute. Questions and answers: Action to Control Cardiovascular Risk in Diabetes (ACCORD) study. March 15, 2010. Available at: http://www.nhlbi.nih.gov/health/prof/heart/other/accord/ q_a.htm. Accessed April 24, 2012

10. Cromwell J, McCall N, Burton J. Evaluation of Medicare Health Support chronic disease pilot program. Health Care Financ Rev. 2008;30(1):47-60

11. Fairman KA. Why hypotheses informed by observation are often wrong: results of randomized controlled trials challenge disease management strategies based on epidemiological evidence. J Manag Care Pharm. 2011;17(3):22431. Available at: http://www.amcp.org/WorkArea/DownloadAsset. aspx?id=8974.

12. Fairman KA. Peeking inside the statistical black box: how to analyze quantitative information and get it right the first time. J Manag Care Pharm. 2007;13(1):70-74. Available at: http://www.amcp.org/WorkArea/ DownloadAsset. aspx?id=7508.

13. Weitzman L. The Divorce Revolution: The Unexpected Social and Economic Consequences for Women and Children in America. New York: Free Press;1985.

14. Webster K. Post-divorce wealth gap was wrong, agrees author. May 17, 1996. The Seattle Times. Available at: http://community.seattletimes. nwsource.com/archive/?date $=19960519 \&$ \&lug=2329984. Accessed April 24, 2012

15. Peterson RR. A re-evaluation of the economic consequences of divorce. American Sociological Review. 1996;61:528-36.

16. Weitzman LJ. The economic consequences of divorce are still unequal: comment on Peterson. American Sociological Review. 1996;61:537-38.
17. McNeely CA. Lagging behind the times: parenthood, custody, and gender bias in the family court. Florida State University Law Review. 1998;25:893-956. Available at: http://www.law.fsu.edu/journals/lawreview/ downloads/254/mcneely.pdf. Accessed April 26, 2012.

18. Hanchate A, Kronman AC, Young-Xu Y, Ash AS, Emanuel E. Racial and ethnic differences in end-of-life costs: why do minorities cost more than whites? Arch Intern Med. 2009;169(5):493-501.

19. Maletta H. Weighting. March 12, 2007. Available at: http://www.spsstools.net/Tutorials/WEIGHTING.pdf. Accessed April 24, 2012.

20. Miller JE. The Chicago Guide to Writing about Multivariate Analysis. Chicago, IL: University of Chicago Press; 2005.

21. Vandenbroucke JP, von Elm E, Altman DG, et al. Strengthening the Reporting of Observational Studies in Epidemiology (STROBE): explanation and elaboration. PLoS Med. 2007;4(10):e296. Available at: http://www. plosmedicine.org/article/info\%3Adoi\%2F10.1371\%2Fjournal.pmed.0040297. Accessed April 24, 2012.

22. Bosco JL, Silliman RA, Thwin SS, et al. A most stubborn bias: no adjustment method fully resolves confounding by indication in observational studies. J Clin Epidemiol. 2010;63(1):64-74. Available at: http://www.ncbi.nlm.nih. gov/pmc/articles/PMC2789188/?tool=pubmed. Accessed April 24, 2012

23. Stukel TA, Fisher ES, Wennberg DE, Alter DA, Gottlieb DJ, Vermeulen MJ. Analysis of observational studies in the presence of treatment selection bias: effects of invasive cardiac management on AMI survival using propensity score and instrumental variable methods. JAMA 2007;297(3):278-85. Available at: http://www.ncbi.nlm.nih.gov/pmc/articles/ PMC2170524/?tool=pubmed. Accessed April 24, 2012.

24. Leslie RS, Ghomrawi H. The use of propensity scores and instrumental variable methods to adjust for treatment selection bias. SAS Global Forum 2008. Available at: http://www2.sas.com/proceedings/forum2008/366-2008. pdf. Accessed April 24, 2012

25. Peng CJ, Lee KL, Ingersoll GM. An introduction to logistic regression analysis and reporting. Journal of Educational Research. 2002;96(1):3-14. Available at: http://bit.csc.lsu.edu/ jianhua/emrah.pdf. Accessed April 24, 2012

26. Fairman KA. Differentiating effective data mining from fishing, trapping, and cruelty to numbers. J Manag Care Pharm. 2007;13(6):517-27. Available at: http://www.amcp.org/data/jmcp/pages\%20517-27.pdf.

27. Barbuto JP. Categorizing patients from medical claims data-the influence of GIGO. J Manag Care Pharm. 2004;10(6):559-60. Available at: http:// www.amcp.org/data/jmcp/Letters_559-566.pdf.

28. Cox ER, Henderson R, Motheral BR. Health plan member experience with point-of-service prescription step therapy. J Manag Care Pharm. 2004;10(4):291-98. Available at: http://www.amcp.org/data/jmcp/ Research-291-298.pdf.

29. EQUATOR network. Library of health research reporting. Available at: http://www.equator-network.org/resource-centre/library-of-health-researchreporting/. Accessed April 23, 2012.

30. Weeks G. Facing failure: the use (and abuse) of rejection in political science. PSOnline. 2006;39(4):879-82. Available at: http://clas-pages.uncc.edu/ gregory-weeks/files/2012/04/WeeksG_2006PSarticle.pdf. Accessed April 24, 2012.

31. Wilson JD. Peer review and publication: Presidential address before the 70th Annual Meeting of the American Society for Clinical Investigation. J Clin Invest. 1978;61(6):1697-701. Available at: http://www.ncbi.nlm.nih.gov/ pmc/articles/PMC372697/pdf/jcinvest00666-0281.pdf. Accessed April 24, 2012

32. Guyatt GH, Oxman AD, Vist GE, et al; GRADE Working Group. GRADE: an emerging consensus on rating quality of evidence and strength of recommendations. BMJ. 2008;336(7650):924-26. Available at: http://www. ncbi.nlm.nih.gov/pmc/articles/PMC2335261/?tool=pubmed. Accessed April $26,2012$. 